\section{Thrombotic Complications at Altitude}

\section{To the Editor:}

Dr Bogdasarian ${ }^{1}$ suggests that climbers use low molecular weight heparin (LMWH) to prevent thrombotic complications on peak climbs over $6000 \mathrm{~m}$. I think that this is an impractical and dangerous suggestion. It is impractical because this would necessitate carrying significant liquid medication, which would have to be protected from freezing. It is dangerous because there are also hemorrhagic phenomena that occur at high altitude. The availability of LMWH to treat deep venous thrombosis (DVT) or even pulmonary embolus (PE) at altitude may be advantageous.

The use of LMWH to prevent DVT in high-risk individuals is well established. Such high-risk patients include those who have already had a DVT; patients who are hospitalized, with reduced mobility and risk factors for DVT; and those who undergo surgery carrying a high risk of DVT, such as hip or knee replacement. Using LMWH for DVT prophylaxis during long airline flights has also been suggested. In each case, the risk of DVT must be balanced against the risk of using LMWH.

There is definitely an increased risk of thrombotic conditions in climbers at high altitudes. A number of case reports highlight these risks, especially in extreme climbing, and certainly on expeditions to 8000 -m peaks. For example, on the American expedition to K2 in 1953, one of the climbers, Art Gilkey, developed life-threatening pulmonary embolism, diagnosed clinically, and died during an accident while his fellow climbers were attempting to evacuate him. ${ }^{2}$ The risk of more moderate climbs in the 6000- and even 7000-m range is much lower.

Risk factors for DVT in high-altitude climbing include immobility, especially during storms, dehydration, and polycythemia. Yet most climbers do not develop clinically evident DVT. The patient with cerebral venous thrombosis described by Fujimaki et $\mathrm{al}^{3}$ was severely polycythemic. The report of superior sagittal sinus thrombosis by Boulos et $\mathrm{al}^{4}$ occurred at about $3000 \mathrm{~m}$ in a patient with protein $\mathrm{C}$ deficiency. Long stays at altitude also carry a risk of venous thrombosis. The risk of stroke and other thrombotic complications during long residence at altitude is highlighted by 2 descriptions of the same patient population in India. ${ }^{5,6}$

Balanced against these low risks for DVT are the risks for hemorrhagic phenomena. The retinal phenomena alluded to by Dr Bogdasarian are most commonly retinal hemorrhages, which are quite common. The incidence may be over $50 \%$ at $5300 \mathrm{mb}^{7}$ and $100 \%$ above 7600 $\mathrm{m} .{ }^{8}$ Subarachnoid hemorrhages have also been described at altitude.9,10 There is no evidence of a role for venous thromboembolism in high-altitude cerebral edema.

Ken Zafren, MD, FACEP

Anchorage, AK, USA

\section{References}

1. Bogdasarian MA. Climbers at altitude: thrombotic conditions and maintaining adequate nutrition [letter]. Wilderness Environ Med. 2004;154.

2. Houston CS, Bates RH. K2: The Savage Mountain. Seattle, WA: The Mountaineers; 1954.

3. Fujimaki T, Matsutani M, Asai A, Kohno T, Koike M. Cerebral venous thrombosis due to high-altitude polycythemia: case report. J Neurosurg. 1986;64:148-150.

4. Boulos P, Courokis C, Balke G. Superior sagittal sinus thrombosis occurring at high altitude associated with protein C deficiency. Acta Haematol. 1999;102:104-106.

5. Jha SK, Anand AC, Sharma V, Kumar N, Adya CM. Stroke at high altitude: Indian experience. High Alt Med Biol. 2002;1:21-27.

6. Anand AC, Jha SK, Saha A, Sharma V, Adya CM. Thrombosis as a complication of extended stay at high altitude. National Med J India. 2001;14:197-201.

7. McFadden D, Houston C, Sutton J, et al. High altitude retinopathy. JAMA. 1981;245:581-586.

8. Rock P, Meehan R, Malconian MK, et al. Operation Everest II: incidence of retinal pathology during a simulated ascent of Mt. Everest. Fed Proc. 1986;45:1030.

9. Dickinson J, Heath D, Gosney J, et al. Altitude-related deaths in seven trekkers in the Himalayas. Thorax. 1983; 38:646-656.

10. Litch JA, Basnyat B, Zimmerman M. Subarachnoid hemorrhage at altitude. West J Med. 1997;167:180-181.

\section{Nutrition at Altitude}

\section{To the Editor:}

Dr Bogdasarian has raised an interesting thought on circumventing some of the problems associated with highaltitude nutrition. Although an elemental, chemically defined diet would be more efficiently absorbed in the sense that it would require less energy to process the nutrients ingested and perhaps lower to a small degree the oxygen requirement associated with digestion, this may not be the critical limitation to metabolism at altitude. At high altitude, the lack of oxygen limits energy metabolism and power output at the same time that anorexia works to reduce the ingestion of food. If a person were determined enough to ingest a defined elemental diet, the person would probably be determined enough to ingest more palatable food, which would not require that much extra energy expenditure for its digestion (the 
thermic effect of food is actually rather small — typically $7 \%-10 \%$ of the calories), so the energy gain from circumventing energy costs of digestion would be small.

I do agree with the "simple is better" implication in Dr Bogdasarian's suggestion. I don't think a "heavy" meal at high altitude offered to a person gasping for breath and severely anorexic is advised. A high-carbohydrate drink and a vitamin pill might be more in order.

I think Dr Bogdasarian and I could perhaps arrive at a compromise: if freezing could be prevented, a complete liquid meal, such as Ensure carried in flexible pouches inside the parka with flexible tubes for easy consumption (similar to a "camelback"), would go a long way to providing essential energy and other nutrients and would be a much more palatable semidefined diet to drink at altitude, even if a person were somewhat anorexic. If a person were so debilitated as to not be able to eat at all, enteral nutrition designed for tube feeding applications is probably not the answer; the person should be sent to a lower elevation to acclimate before continuing.
Wayne Askew, PhD Salt Lake City, UT, USA 